\title{
HABITAT CHARACTERISTICS AND POPULATION STRUCTURE OF DIPTERIS CHINENSIS, A RELICT PLANT IN CHINA
}

\author{
OUYANG, K. T. ${ }^{1,2}-$ REN, H. ${ }^{1,2^{*}}-$ XU, Z. H. ${ }^{1,2}-$ WANG, F. G. ${ }^{1}$ - LIU, S. Z. ${ }^{1}-$ ZHANG, Q. M. ${ }^{1}-$ \\ HU, M. F. ${ }^{3}-$ ZHANG, Y. J. $^{3}-$ LIU, Z. J. $^{3}-$ GUO, Q. F. ${ }^{4}$ \\ ${ }^{1}$ Key Laboratory of Applied Botany, South China Botanical Garden, Chinese Academy of \\ Sciences, Guangzhou 510650, China \\ ${ }^{2}$ University of Chinese Academy of Sciences, Beijing 100049, China \\ ${ }^{3}$ Nanling National Nature Reserve Administration, Shaoguan 512727, China \\ ${ }^{4}$ Eastern Forest Environmental Threat Assessment Center, USDA Forest Service, Research \\ Triangle Park NC27709, USA \\ *Corresponding author \\ e-mail: renhai@scbg.ac.cn
}

(Received 25 $5^{\text {th }}$ Dec 2020; accepted $3^{\text {rd }}$ Mar 2021)

\begin{abstract}
Dipteris chinensis Christ is endemic to China and is at risk of extinction due to anthropogenic disturbance and climate change. Our understanding of $D$. chinensis population structure and habitat is poor. Here, we investigated the habitat characteristics and population structure of a $D$. chinensis community at Chenjia in the Nanling National Nature Reserve, southern China. We conducted a principal component analysis followed by correlation analysis to identify the main habitat factors associated with the abundance of young $D$. chinensis plants. We found that the species grew in a warm and humid environment under evergreen coniferous and broad-leaved mixed forests. Young D. chinensis abundance was positively correlated with the litter standing crop, soil organic matter content, and soil total nitrogen. However, the production of new $D$. chinensis plants appeared to be limited by a low reproduction rate (as evidenced by a population age structure skewed toward mature plants) and interspecific competition. These findings are useful for directing and prioritizing future conservation efforts.
\end{abstract}

Keywords: conservation, fern, community structure, habitat factors, correlation analysis

\section{Introduction}

Habitat loss and fragmentation caused by human disturbance coupled with global climate change threaten plant diversity worldwide (Ren et al., 2019). Many countries have made direct efforts for the conservation of flowering plant diversity, especially the protection of rare and endangered plants (Thomas and Stohlgren, 2013; Dong et al., 2017) but other smaller plant groups such as ferns are often left under-protected. Rare and endangered ferns (pteridophytes) play a key role in maintaining overall plant diversity and ecosystem stability, and are critical for understanding species origin, evolution, and classification (Murakami et al., 2005). Pteridophytes also have economic values as food and medicine and as ornamental plants (Lu, 2007). In addition, because ferns are sensitive to changes in the climate and other environment, they may serve as indicators of environment change (Lu, 2007). Nevertheless, few studies have examined the population structure and habitat characteristics of rare and endangered pteridophytes.

Dipteris chinensis Christ (Cheng, 2005) is a perennial herb in the family Dipteriaceae. Its Chinese common name, octopus fern, reflects the unique shape of its leaves (Fig. 1). Like many other pteridophytes, $D$. chinensis is a relict species and is endemic to China 
with limited distributions in Chongqing, Guizhou, Guangxi, Hunan, and Guangdong Provinces. Its rhizome is long and transverse, woody, with one leaf. Plant height is mostly between 0.6 and $2.0 \mathrm{~m}$. Its leaves are papery and double fan-shaped, i.e., the middle part of each leaf is divided to form two symmetrical fans. Each fan is further divided into 4-5 unequal lobes, and the leaf width is 40-60 $\mathrm{cm}(\mathrm{Lu}, 2007)$. Pteridophytes include only eight species belonging to one genus (Dipteris) and have narrow geographical distributions and quite limited genetic diversity (Zhou, 2015; Chen, 2016). Studies of pteridophytes include taxonomic revision and phylogenetic evaluation of the Dipteridaceae (Lu and Tian, 2011; Choo and Escapa, 2018), morphology of the genus Dipteris (Chandra and Kaur, 1993), and extraction and application of pteridophyte-derived compounds (Wang, 2010). This species has not been protected except for individuals growing in the natural reserve. No reports are available, however, on the population structure and habitat of $D$. chinensis.
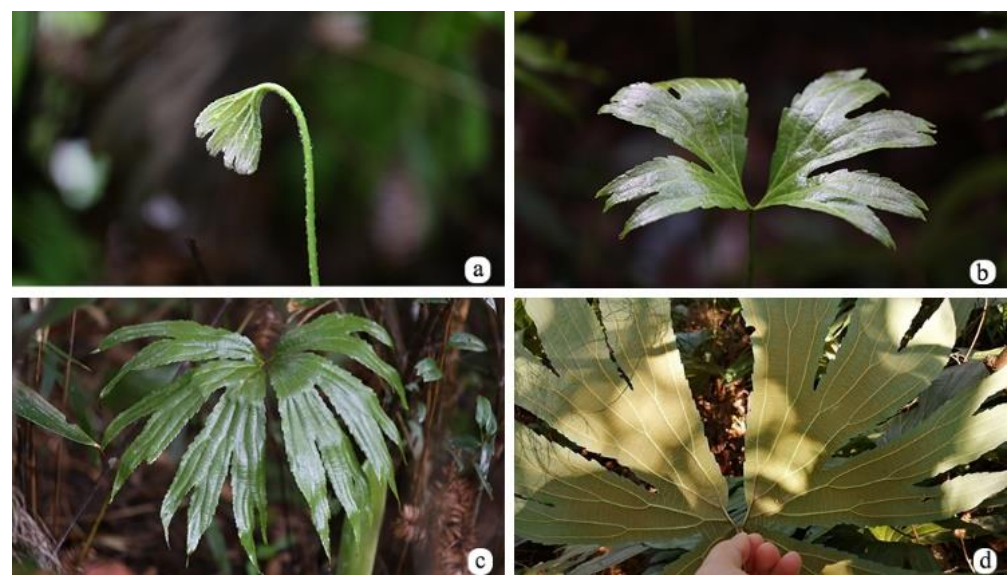

Figure 1. Dipteris chinensis age classes. (a) Young age class; (b) Middle age class; (c) Old age class; and $(d)$ The abaxial surface of a mature sporophyll

In this research, we studied the habitat characteristics and population structure of D. chinensis at the Chenjia management station of the Nanling National Nature Reserve. We attempted to answer the following questions: (1) Which habitat factors control the abundance of young D. chinensis? and (2) Does the age structure of the D. chinensis population indicate population trend (increasing or decreasing)? The results may contribute to the protection and sustainable utilization of $D$. chinensis.

\section{Materials and Methods}

\section{Study site}

This investigation was conducted at the Chengjia of Nanling National Nature Reserve of Yangshan County, Guangdong Province, China $\left(24^{\circ} 42^{\prime}-24^{\circ} 47^{\prime} \mathrm{N}, 112^{\circ} 51^{\prime}-112^{\circ} 57^{\prime} \mathrm{E}\right)$ (Fig. 2). The study site is located in a mountainous area at the altitude of $800-900 \mathrm{~m}$ and has a subtropical monsoon climate (Wang et al., 2007). The mean annual temperature is $17.7^{\circ} \mathrm{C}$, with the highest temperature of $34.4^{\circ} \mathrm{C}$ in July and the lowest temperature of $-4^{\circ} \mathrm{C}$ in January (1954) (Liu et al., 2020). The mean annual relative humidity is $84 \%$, and the mean annual precipitation is about $1705 \mathrm{~mm}$. Frost and snow occur in winter. The area has a yellow-red soil (Wang et al., 2013). The main vegetation type at the nature reserve is subtropical mountain evergreen broadleaved forest. 


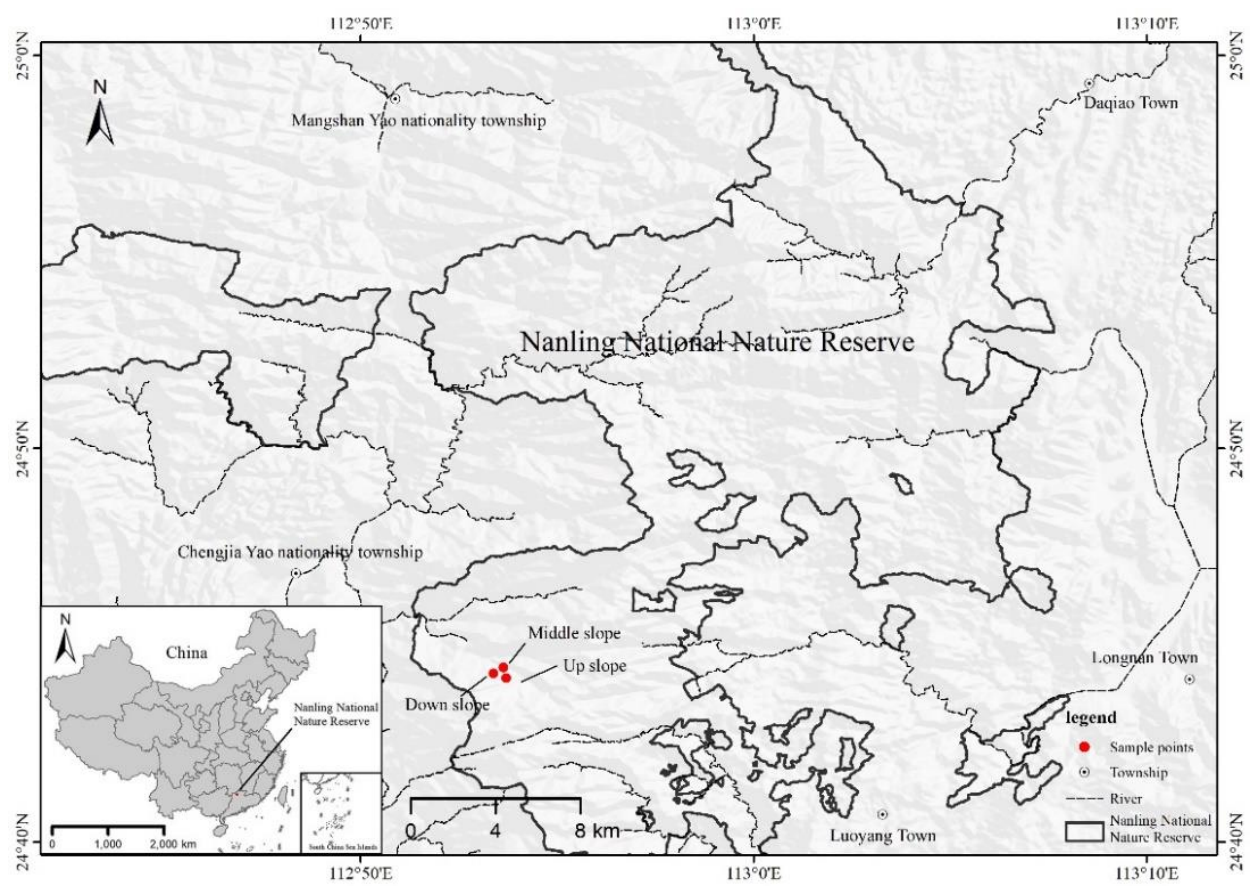

Figure 2. The geographical location of the sampling sites of Dipteris chinensis at the Nanling National Nature Reserve, southern China. Red polygon in small map indicates the Nanling National Nature Reserve. Sample plots were set in red dots

\section{Field survey and laboratory analysis}

In June 2020, we established three $20 \mathrm{~m} \times 20 \mathrm{~m}$ plots on slopes of the $D$. chinensis distribution area (Table A1), in addition to measuring the altitude and slope of each plot, we identified all tree species in $20 \mathrm{~m} \times 20 \mathrm{~m}$ plot and determined their numbers and the height, as well as trunk and crown diameters of each tree. We also identified all shrubs in one $5 \mathrm{~m} \times 5 \mathrm{~m}$ subplot (for shrubs) in the center of each plot, and identified all herbs in two $1 \mathrm{~m} \times 1 \mathrm{~m}$ quadrats (for herbs) in each subplot (Zhou, 2019). To investigate the age structure of the $D$. chinensis population, we counted the number of individuals in each age class (see Fig. 1; a young sporophyte has hair, light green leaf and stem, no notch and sporangium; the sporangia appeared in the middle age sporophyte than in the young stage; an old sporophyte has black or black brown stem and its leaf with deep notch is leathery, glabrous, green, and has many orange black spots attached on the abaxial surface) in each of the three subplots. To identify the dominant plant species in each plot, we calculated the importance values $(I V)$ and niche breadth $(B i)$ for each plant species in each plot. We adopted the method by $\mathrm{Li}$ (2018) and Ge (2008), and calculated $I V$ and Bi with Eq.1, Eq.2 and Eq.3.

$$
\begin{gathered}
I V=\frac{\text { Relative density }+ \text { Relative coverage }+ \text { Relative frequency }}{3} \\
I V=\frac{\text { Relative density }+ \text { Relative dominance }+ \text { Relative frequency }}{3} \\
B i=\frac{1}{\sum_{j}^{r}(n i j / N i)^{2}}
\end{gathered}
$$


where $B i$ is the niche breadth of species $i, n_{i j}$ is the number of resource states $j$ used by species $i$ (in this paper, the $I V$ of species in the plot), $N i$ is the total amount of species $i$ (in this paper, the sum of $I V$ of species in all plots), and $r$ is the number of resource classes (number of plots).

Three species diversity indices of Shannon-wiener index (Magurran, 1988), Simpson index (Simpson, 1949), Pielou's index (Qian and Ma, 1994) were calculated with Eq.4, Eq.5 and Eq.6.

$$
\begin{gathered}
H_{e}^{\prime}=-\sum_{i=1}^{S} P_{i} \operatorname{In} P_{i}, P_{i}=\frac{n_{i}}{N} \\
\mathrm{D}=1-\sum_{i=1}^{S} P_{i}^{2} \\
J_{e}=\frac{H^{\prime} e}{H^{\prime} \max } H_{\text {max }}^{\prime}=\operatorname{In} S
\end{gathered}
$$

where $P_{i}$ was the relative importance of species $i$ in the quadrat, and $S$ was the number of species.

To examine the relationship between the environmental factors and young $D$. chinensis abundance, we randomly collected soil samples from nine points to $10 \mathrm{~cm}$ depth, and three soil ring knife samples in each of the $20 \times 20 \mathrm{~m}$ plots (Zhang, 2018); leaf litter was removed before soil samples were collected. The three soil samples from each plot were combined to yield one composite soil sample per plot, i.e., three composite soil samples (down slope, middle slope and upslope) and were transported to the laboratory for analyses. The contents of soil organic matter, soil total nitrogen, soil total phosphorus, and soil total potassium were measured by the dichromate method, the semi-micro Kjeldahl method, molybdenum antimony colorimetry, and atomic absorption spectrophotometry (ContrAA700, Analytik Jena, Germany), respectively. Soil pH (10 ml soil in $25 \mathrm{ml}$ of water) was measured with a $\mathrm{pH}$ meter. Soil water content in the composite samples and bulk density for the ring knife samples were determined by measuring soil mass before and after oven-drying (Liu, 1996).

We collected litter samples from three randomly selected $1 \mathrm{~m} \times 1 \mathrm{~m}$ quadrats under D. chinensis. The masses of the samples were determined before and after drying at $65^{\circ} \mathrm{C}$ (Liu et al., 2020). In September 2020, we measured the leaf area index (LAI; an indirect indication of light transmittance under the forest canopy) with an LAI-2200C instrument (LI-COR, USA) at 15 randomly selected points in each plot at 4:00 pm (Zhou, 2011).

\section{Data analysis}

To identify the life forms and the floristic phytogeography types of all plants in the studied community, we used the Raunkiaer lifestyle system (1934) and Floristics of Seed Plants from China (Li, 1996; Wu et al., 2010). We used the Vegan package in R language to analyze the species diversity (Zhang, 2010). We also performed two separate analyses to determine the relationship between habitat factors and young $D$. chinensis abundance. We then performed principal component analyses (PCA) in the Vegan package followed by Pearson correlation analysis in the Pysch package to identify the main habitat factors associated with the abundance of young D. chinensis. All statistical analyses were performed in $\mathrm{R}$ 3.6.3. 


\section{Results}

\section{Community habitat characteristics}

Species composition

A total of 52 species of vascular plants (28 families, 2 ferns, 1 lycophyte, 2 gymnosperms, and 47 angiosperms) were found in the D. chinensis community (Table 1). The species composition at the down slope and middle slope plots was similar (Fig. 3). The abundant families were Theaceae, Ericaceae, lauraceae, and Aquifoliaceae. Most species were represented by trees $(88 \%)$, and others were herbs and vines $(11 \%)$. Among vascular plants, more species were tropical than temperate, including 21 tropical families and 4 temperate families (Qin, 1978; Li, 1996; Zang, 1998; Wu et al., 2010). On the other hand, 33 genera were represented by 11 distribution types, most of which were tropical (Table 2).

Table 1. Species composition of the Dipteris chinensis community

\begin{tabular}{c|c|c|c|c|c|c}
\hline Type & $\begin{array}{c}\text { Number of } \\
\text { families }\end{array}$ & $\begin{array}{c}\text { Percentage of } \\
\text { all families }\end{array}$ & $\begin{array}{c}\text { Number of } \\
\text { genera }\end{array}$ & $\begin{array}{c}\text { Percentage of } \\
\text { all genera }\end{array}$ & $\begin{array}{c}\text { Number of } \\
\text { species }\end{array}$ & $\begin{array}{c}\text { Percentage of } \\
\text { all species }\end{array}$ \\
\hline Fern & 2 & 7.14 & 2 & 6.06 & 2 & 3.85 \\
Gymnosperm & 2 & 7.14 & 2 & 6.06 & 2 & 3.85 \\
Angiosperm & 23 & 82.14 & 28 & 84.85 & 47 & 90.38 \\
Lycophytes & 1 & 3.57 & 1 & 3.03 & 1 & 1.92 \\
Total & 28 & 100.00 & 33 & 100.00 & 52 & 100.00 \\
\hline
\end{tabular}

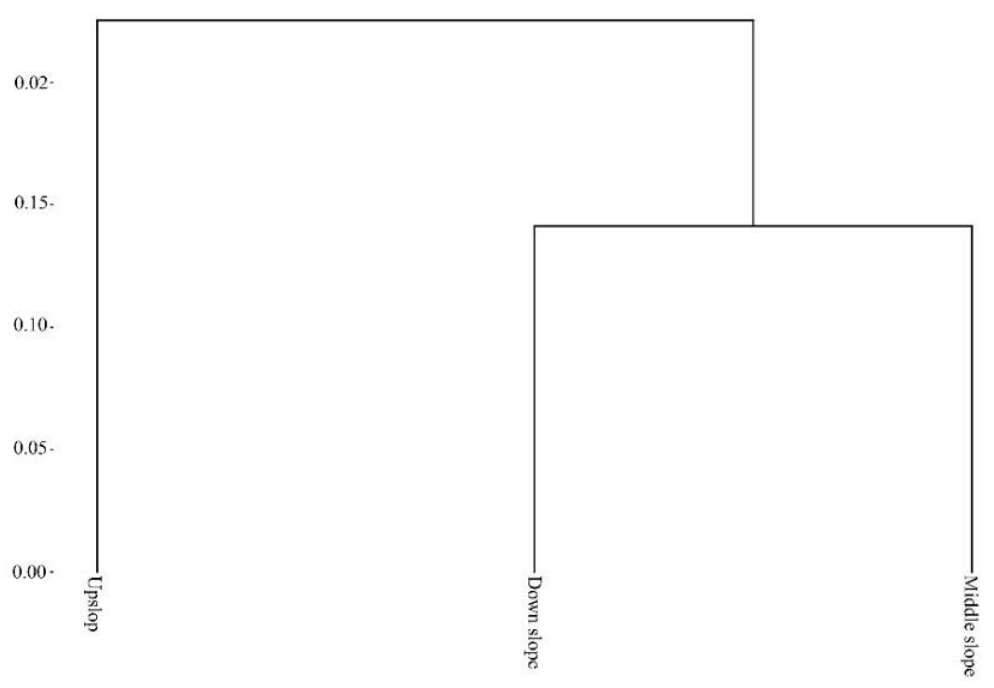

Figure 3. The cluster diagram of sample plots of Dipteris chinensis communities at the Nanling National Nature Reserve, Southern China

\section{Composition of plant life form}

Most of the vascular plants in the community were phanerophytes (Fig. 4). Microphanerophytes were the most abundant, followed by mesophanerophytes, nanophanerophytes, chamaephytes, and megaphanerophytes. 
Table 2. Types of distribution of families and genera in the Dipteris chinensis community

\begin{tabular}{c|c|c|c|c}
\hline Distribution type & $\begin{array}{c}\text { Number of } \\
\text { families }\end{array}$ & $\begin{array}{c}\text { Percentage of } \\
\text { all families }\end{array}$ & $\begin{array}{c}\text { Number of } \\
\text { genera }\end{array}$ & $\begin{array}{c}\text { Percentage of } \\
\text { all genera }\end{array}$ \\
\hline 1. Cosmopolitan & 3 & - & 0 & - \\
2. Pantropic & 16 & 57.14 & 5 & 15.15 \\
3. Tropics \& Subtropics East Asia \& & 0 & 0.00 & 4 & 12.12 \\
Tropical America Disjuncted & 1 & 3.57 & 1 & 3.03 \\
4. Old World Tropics & 1 & 3.57 & 4 & 12.12 \\
5. Tropics Asia to Tropics Australasia & 0 & 0.00 & 2 & 6.06 \\
Oceania & 3 & 10.71 & 6 & 18.18 \\
6. Tropics Asia to Tropics Africa & 21 & 84.00 & 22 & 66.67 \\
7. Tropics Asia & 3 & 10.71 & 3 & 9.09 \\
Subtotal of tropical elements (2-7) & 1 & 3.57 & 5 & 15.15 \\
8. North Temperate & 0 & 0.00 & 0 & 0.00 \\
9. East Asia \& North America Disjuncted & 0 & 0.00 & 1 & 3.03 \\
10. Old World Temperate & 0 & 0.00 & 0 & 0.00 \\
11. Temperate Asia & 0 & 0.00 & 0 & 0.00 \\
12. Mediterranean, West to Central Asia & 0 & 0.00 & 0 & 0.00 \\
13. Central Asia & 0 & 0.00 & 2 & 6.06 \\
14. East Asia & 4 & 19.05 & 11 & 33.33 \\
\hline 15. Endemic to China & &
\end{tabular}

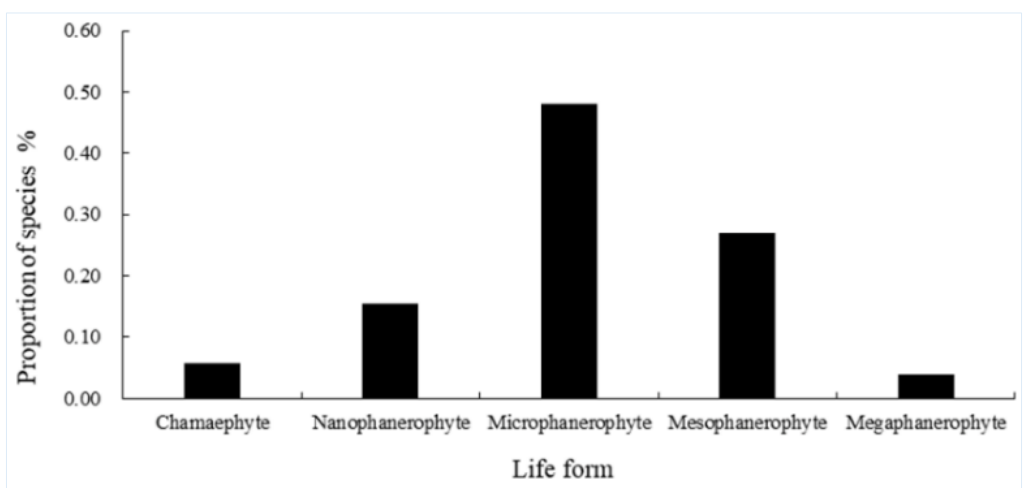

Figure 4. Proportions of plant species in the Dipteris chinensis community at the Nanling National Nature Reserve, southern China represented by the indicated life forms

\section{Species diversity}

In terms of diversity, the middle slope had the highest species richness, ShannonWiener diversity index, and Simpsons index, but the low Pielou index (Table 3). The down slope had the lowest species richness, Shannon-Wiener diversity index, and Simpsons index, but the highest Pielou index. 
Table 3. Species diversity of the Dipteris chinensis community (Mean) at the Nanling National Nature Reserve, southern China

\begin{tabular}{c|c|c|c|c}
\hline Site & Species richness/plot & $\begin{array}{c}\text { Shannon-Weinner } \\
\text { index }\end{array}$ & Simpsons index & Pielou index \\
\hline Down slope & 21 & 2.58 & 0.89 & 0.85 \\
Middle slope & 39 & 2.93 & 0.91 & 0.80 \\
Upslope & 28 & 2.64 & 0.90 & 0.80 \\
Total & 52 & 3.03 & 0.91 & 0.78 \\
\hline
\end{tabular}

\section{Species importance and niche breadth}

The dominant species in the $D$. chinensis community was Cunninghamia lanceolata, followed by Rhododendron ovatum, Eurya macartneyi, and Machilus chinensis (Table 4). The importance value for all other plant species was less than 0.10 . The importance value and niche breadth were the same for Dipteris chinensis, Diplopterygium laevissimum, and Indocalamus latifolia.

Table 4. Importance value and niche breadth of the top 20 species in Dipteris chinensis communities at the Nanling National Nature Reserve, southern China

\begin{tabular}{c|c|c|c}
\hline Number & Species & Importance value & Niche breadth \\
\hline 1 & Cunninghamia lanceolata & 0.57 & 2.67 \\
2 & Rhododendron ovatum & 0.22 & 2.69 \\
3 & Eurya macartneyi & 0.18 & 2.8 \\
4 & Machilus chinensis & 0.11 & 2.54 \\
5 & Adinandra glischroloma & 0.09 & 2.81 \\
6 & Castanopsis fissa & 0.08 & 2.76 \\
7 & Syzygium buxifolium & 0.07 & 2.47 \\
8 & Machilus phoenicis & 0.07 & 2.84 \\
9 & Castanopsis faberi & 0.07 & 1.72 \\
10 & Castanopsis eyrei & 0.07 & 1.24 \\
11 & Symplocos lancifolia & 0.06 & 1.85 \\
12 & Daphniphyllum oldhamii & 0.06 & 2.85 \\
13 & Vaccinium carlesii & 0.05 & 2.66 \\
14 & Diplopterygium laevissimum & 0.05 & 2.99 \\
15 & Indocalamus longiauritus & 0.05 & 2.99 \\
16 & Dipteris chinensis & 0.05 & 2.99 \\
17 & Rhododendron cavaleriei & 0.04 & 1.57 \\
18 & Elaeocarpus chinensis & 0.04 & 2.65 \\
19 & Dendropanax proteus & 0.03 & 2.91 \\
20 & Symplocos stellaris & 0.03 & 2.91 \\
\hline
\end{tabular}

\section{Soil factor and leaf area index}

The $D$. chinensis community was located on a slope of 15-30 degrees. Soil bulk density was $0.61 \pm 0.31 \mathrm{~g} \mathrm{~cm}^{-3}$ (mean $\pm \mathrm{SD}$ ), and the mean soil moisture content was $29 \pm 7 \%$. Other means and standard deviations were $4.67 \pm 0.09$ for soil $\mathrm{pH}, 5.54 \pm 0.74 \%$ for soil 
organic matter content, $4.09 \pm 0.65 \mathrm{~g} \mathrm{~kg}^{-1}$ for soil nitrogen content, $0.19 \pm 0.03 \mathrm{~g} \mathrm{~kg}^{-1}$ for soil phosphorus content, and $0.98 \pm 0.22 \mathrm{~g} \mathrm{~kg}^{-1}$ for soil potassium content. The litter standing crop (dry mass) was $1.14 \pm 0.25 \mathrm{~kg} \mathrm{~m}^{-2}$. The mean leaf area index of the community was $1.75 \pm 0.81$.

\section{Relationship between young D. chinensis abundance and habitat factors}

Results from principal component analyses (PCA) using 12 selected habitat factors (Table 5) indicated that the first three axes (PCA1, 2 and 3) explained 29\%, 25\% and 22\%, respectively, of the variation in the abundance of young $D$. chinensis. These three axes together explained $76 \%$ of the total variation. The first axis was significantly related to soil organic matter, soil total nitrogen and soil $\mathrm{pH}$, we suspect the young $D$. chinensis tended to grow in habitats with high soil nutrient content. The second axis was significantly correlated with soil total potassium, population density and litter standing crop, which indicates the young fern prefers to live in these habitats with higher soil potassium and relative humidity. The third axis was significantly associated with leaf area index and population coverage, suggesting that $D$. chinensis adapted to more shade environment.

Table 5. The loading matrix of habitat factors on the first two axes of PCA of young Dipteris chinensis community at Chenjia in the Nanling National Nature Reserve, southern China

\begin{tabular}{c|c|c|c}
\hline \multirow{2}{*}{ Habitat factor } & \multicolumn{3}{|c}{ Principal component } \\
\cline { 2 - 4 } & $\mathbf{1}$ & $\mathbf{2}$ & $\mathbf{3}$ \\
\hline Soil organic matter & 0.94 & -0.10 & -0.16 \\
Soil total nitrogen & 0.93 & -0.09 & 0.17 \\
Soil total phosphorus & 0.2 & 0.26 & -0.83 \\
Soil total potassium & -0.35 & 0.87 & -0.22 \\
Soil pH & 0.87 & 0.20 & 0.12 \\
Soil water content & 0.69 & -0.50 & 0.08 \\
Soil density & 0.11 & 0.23 & 0.49 \\
Litter standing crop & 0.14 & 0.77 & 0.18 \\
Leaf area index & 0.27 & -0.15 & 0.81 \\
Slope & 0.48 & -0.83 & 0.20 \\
Population density & 0.12 & 0.71 & 0.29 \\
Population coverage & -0.03 & 0.42 & 0.82 \\
Eigenvalue & 3.51 & 3.17 & 2.54 \\
Percentage of variance (\%) & 29.00 & 25.00 & 22.00 \\
Percentage of cumulative variance (\%) & 29.00 & 54.00 & 76.00 \\
\hline
\end{tabular}

We then conducted a Pearson correlation analysis of the relationship between young D. chinensis abundance and those habitat factors with the large loading values on the first three axes of PCA. The results showed that there was a significant positive correlation between young $D$. chinensis abundance and the litter standing crop $(\mathrm{P}=0.05 \leq 0.05)$, soil organic matter content $(\mathrm{P}=0.01 \leq 0.01)$, soil total nitrogen $(\mathrm{P}=0.03<0.05)$. 


\section{Population structure of $D$. chinensis}

The $D$. chinensis population was skewed toward the mature age class, and young plants represented only a small proportion of the population (Fig. 5).

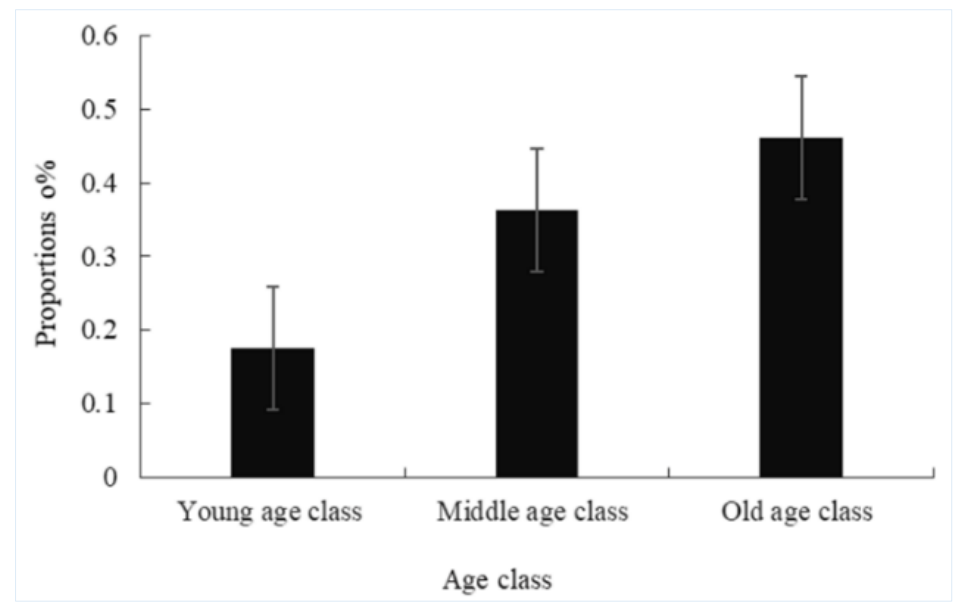

Figure 5. Age structure of Dipteris chinensis populations at the Nanling National Nature Reserve, southern China

\section{Discussion}

\section{Relationship between the young $D$. chinenesis and habitat factors}

Dipteris chinensis prefers to grow in a warm and humid environment (Zhou et al., 2015). In our study, consistent with previous reports that $D$. chinensis prefers to grow in a warm and humid environment (Chen, 2016), we found that the D. chinensis population in the current study was part of a tropical plant community, and the vascular flora in this community has tropical floristic characteristics (Table 2). At the Nanling National Nature Reserve, where the current research was conducted, D. chinensis is distributed on a northeast-facing hillside at 800 to $900 \mathrm{~m}$. The area has a subtropical monsoon climate with frequent precipitation and high humidity, which promotes the rapid growth of phaenerophytes ( $\mathrm{Li}$ et al., 2017). Consistent with the latter study, we found that the D. chinensis was a member of a plant community dominated by phanerophytes (Fig. 4), which are kinds of large shrubs and trees that support understory plants by maintaining a warm environment in the winter and a cool environment in the summer. By intercepting the strong light in summer and cold winds in the winter, the phanerophyte canopy provides an environment conducive for the survival of $D$. chinensis (Andivia et al., 2018).

We detected a positive correlation between the abundance of young D. chinensis and the litter standing crop. As noted earlier, D. chinensis prefer to grow in a warm and humid environment, and litter covering the soil surface can help maintain soil moisture and temperature (Boeken and Orenstein, 2001; Loydi et al., 2013) and can thereby provide a suitable environment for the clonal growth of $D$. chinensis. We also detected a positive correlation between young $D$. chinensis abundance and the content of soil organic matter as well as soil total nitrogen. As we found that $D$. chinensis in the study formed ramets by rhizomes, however, in the initial phase of pteridophyte clonal growth, the growth process of young sporophytes with poor resistance is dependent on the nutrient supply of the mother plant and the nutrient content originated from the habitat ( $\mathrm{Du}$ et al., 2010; 
Zhang et al., 2019). Indeed, from mother plant to budding sporophyte, the mother plant needs to consume a massive of energy materials (Slade and Hutchings, 1987). Under a suitable environment, the mother plant will allocate more biomass to the rhizome to produce more clonal ramets, on the contrary, it inhibits the growth of rhizome in a barren environment (Huber-Sannwald et al., 1998). In addition, similar results have been found in other studies. Liu (2017) found that the young sporophytes of Dicranopteris pedata died due to insufficiency in nutrients. More importantly, Soil nitrogen is an important limiting factor for plants growth and development (Lars, 2004), which affects the plants distribution to some extent (Wang et al., 2021). Nitrogen plays a principal role in plant life history such as height, and leaf and root tiller growth (Pan, 2012). The clonal propagation of rhizomes increases the number of individuals, indicating the importance of soil nitrogen content for the growth of young D. chinensis.

Dipteris chinensis, I. longiauritus and D. laevissimum in the community have similar niche breadths (Table 4). Their rhizomes absorb more nutrients from soil when they are in the growth peak period, and the limited soil resources may cause interspecific competition. Indocalamus longiauritus, with the strong carbon capture capacity and high water and photosynthesis use efficiency (Montti et al., 2014; Fadrique et al., 2020), has the fastest growth rate of all plants (Pearson et al., 1994). It usually dominates the understory and shows strong competitive advantage compared with the seedlings of other species (Bai et al., 2011). The genus Diplopterygium usually consume large amounts of soil nitrogen during its vigorous period (Ai, 2010). These two herbs (I. longiauritus and D. laevissimum) not only occupy much soil spaces but also seize a tremendous amount of soil nutrients during their growth, therefore are not conducive to the population regeneration of $D$. chinensis.

\section{A declining population of $D$. chinensis}

The $D$. chinensis population is indeed in decline. One possible reason for the decline is that $D$. chinensis cannot generate juvenile sporophytes through spore reproduction due to low soil humidity, and mainly depends on clonal propagation via rhizomes (Sun et al., 2019). However, this regeneration process is affected by its self-conditions (initial costs of mother plants), as shown by Pearson correlation analysis that the amount of soil organic matter and litter standing crop are significantly affecting the young D. chinensis individual; therefore, the supplement of the young fern is reducing. Another explanation for the decline in D. chinensis is competition with Indocalamus longiauritus (a bamboo: Zhao and Yang, 1985: 232) and Diplopterygium laevissimum (Holttum, 1991: 11). The rhizomes of the bamboo spread rapidly on the soil surface to form a root network thus may slow the clonal spread of $D$. chinensis.

\section{Conclusions}

Our study indicates that the litter standing crop, soil organic matter, and soil nitrogen are significantly related to the abundance of young $D$. chinensis. The species shows a declining trend in population size at the Nanling National Nature Reserve in south China, perhaps because of competition with Indocalamus longiauritus and Diplopterygium laevissimum and lack of effective litter coverage on soil surface. In order to protect D. chinensis more effectively, we recommend removing I. longiauritus and adding litter to increase $D$. chinensis abundance. Research is also needed to enhance $D$. chinensis's sexual reproduction. 
Acknowledgements. We thank Zhang Xionghui and Cai Gou for help in the field at the Chenjia Conservation Station in Nanlin National Nature Reserve; Deng shuangwen, Lin Mingchen, Duan Lei, and Liu Hailin for help with the community investigation; and long Qingchun and Mo Hui of the Public Laboratory of South China Botanical Garden for technical assistance with the soil physical and chemical analyses. We also thank Prof. Bruce Jaffee for proof-reading the manuscript.

\section{REFERENCES}

[1] Ai, J. G. (2010): Research on biological and ecological characteristics of Hicriopteris glauca in phyllostachys edulis forest. - Chinese Academy of Forestry.

[2] Andivia, E., Madrigal, G. J., Villar, S. P., Zavala, M. A. (2018): Do adult trees increase conspecific juvenile resilience to recurrent droughts? - Implications for forest regeneration Ecosphere 9(6): e02282.

[3] Bai, K., Jiang, D., Cao, K., Liao, D., Wan, X. (2011): The physiological advantage of an ecological filter species, Indocalamus longiauritus, over co-occurring Fagus lucida and Castanopsis lamontii seedlings. - Ecology Research 26: 15-25.

[4] Boeken, B., Orenstein, D. (2001): The effect of plant litter on ecosystem properties in a Mediterranean semi-arid shrubland. - Journal of Vegetation Science 12(6): 825-832.

[5] Chandra, S., Kaur, S. (1993): Vasculature of the rhizome in the fern genus Dipteris. American Fern Journal 83(2): 71-72.

[6] Chen, Y. X. (2016): The late Triassic Marattiaceae and Dipteridaceae and their palaeoecology in Yipinglang, Yunnan. - Yunnan University.

[7] Cheng, X. (2005): Flora Yunnanica. - Science Press, Beijing 21: 273.

[8] Choo, T. Y. S., Escapa, I. H. (2018): Assessing the evolutionary history of the fern family Dipteridaceae (Gleicheniales) by incorporating both extant and extinct members in a combined phylogenetic study. - American Journal of Botany 105(8): 1315-1328.

[9] Dong, S. Y., Zuo, Z. Y., Yan, Y. H., Xiang, J. Y. (2017): Red list assessment of lycophytes and ferns in China. - Biodiversity 25(07): 765-773.

[10] Du, J., Wang, N., Alpert, P., Yu, M. J., Yu, F. H., Dong, M. (2010): Clonal integration increases performance of ramets of the fern Diplopterygium glaucum in an evergreen forest in southeastern China. - Flora 205(06): 399-403.

[11] Fadrique, B., Veldman, J. W., Dalling, J. W., Clark, L. G., Montti, L., Ruiz-Sanchez, E., Rother, D. C., Ely, F., Farfan-Ríos, W., Gagnon, P., Prada, C. M., García, J. C. C., Saha, S., Veblen, T. T., Londoño, X., Feeley, K. J., Rockwell, C. A. (2020): Guidelines for including bamboos in tropical ecosystem monitoring. - Biotropica 52: 427-443.

[12] Ge, F. (2008): Modern Ecology. - In: Hao, S.-G. (ed.) The distribution of community. Science Press, Beijing.

[13] Holttum, R. E., van Steenis, C. G. G. J., Kebun, R., Lembaga, B., Nasional, R. (1991): Flora Malesiana (Series II). - In: Nijhoff, M., Junk, W. (ed.) Pteridophyta. Boston.

[14] Huber-Sannwald, E., Pyke, D. A., Caldwell, M. M., Durham, S. (1998): Effects of nutrient patches and root systems on the clonal plasticity of a rhizomatous grass. - Ecology 79(7): 2267-2280.

[15] Lars, O. H. (2004): Global organization of terrestrial plant-nutrient interactions. Proceedings of the National Academy of Sciences 101(30): 10849-10850.

[16] Li, X. W. (1996): Floristic statistics and analyses of seed plants from China. - Acta Botanica Yunnanica 18(4): 363-384.

[17] Li, J. X., Xiong, G. M., Xu, W. T., Li, Y. L., Lu, Z. J., Zhao, C. M., Xie, Z. Q. (2017): Composition of plant life forms of subtropical shrubland in China and its correlation with temperature and precipitation. - Chinese Journal of Plant Ecology 41(01): 147-156.

[18] Li, Q. L. (2018): Community characteristics and conservation strategies of endangered plant Adiantum nelumboides X. C. Zhang in three gorges reservoir region. - Southwest University. 
[19] Liu, G. S. (1996): Soil physical and chemical analysis \& description of soil profiles. China Standards Press, Beijing.

[20] Liu, L. T. (2017): Analysis on population patten of Dicranopteris Pedata during spread process. - Beijing Forestry University.

[21] Liu, Z. L., Lu, Y. D., Yao, Y. (2020): Water-holding characteristics of litter and soil of original Korean pine forests stands with different density. - Forest Engineering 36(05): 815.

[22] Liu, Z. J., Ma, X., Xie, Y., Zhou, Z. P., Ma, F. L., Zhang, J. D. (2020): Community Comanagement in Nanling National Nature Reserve. - Protection Forest Science and Technology 11: 50-52.

[23] Loydi, A., Eckstein, R. L., Otte, A., Donath, T. W. (2013): Effects of litter on seedling establishment in natural and semi-natural grasslands: a meta-analysis. - Journal of Ecology 101(2): 454-464.

[24] Lu, S. G. (2007): Pteridology. - Higher Education Press, Beijing, pp. 5-6.

[25] Lu, S. G., Tian, Z. J. (2011): A taxonomic revision of the Dipteridaceae from Yunnan, China. - Plant Science Journal 4(29): 432-434.

[26] Magurran, A. E. (1988): Ecological diversity and its measurement. - Princeton University Press, New jersey.

[27] Montti, L., Villagra, M., Campanello, P. I., Gatti, M. G., Goldstein, G. (2014): Functional traits enhance invasiveness of bamboos over co-occurring tree saplings in the semideciduous Atlantic Forest. - Acta Oecologica-International Journal of Ecology 54: 3644.

[28] Murakami, K., Maenaka, H., Morimoto, Y. (2005): Factors influencing species diversity of ferns and fern allies in fragmented forest patches in the Kyoto city area. - Landscape and Urban Planning 70(3-4): 221-229.

[29] Pan, R. C. (2012): Plant Physiology. - Higher education press, Beijing.

[30] Pearson, A. K., Pearson, O. P., Gomez, I. A. (1994): Biology of the bamboo Chusquea culeou (Poaceae: Bambusoideae) in southern Argentina. - Vegetatio 111(2): 93-126.

[31] Qian, Y. Q., Ma, K. P. (1994): Principle and methods of biodiversity studies. - Chinese scientific and technological Press, Beijing.

[32] Qin, R.-C. (1978): Fern families and genera in China: their system of arrangement and historical origin. - Journal of Systematics and Evolution 16(3): 1-19.

[33] Raunkiær, C. (1934): The life forms of plants and statistical plant geography, being the collected papers of C. RAUNKIÆR. - Oxford University Press, Oxford.

[34] Ren, H., Qin, H. N., Ouyang, Z. Y., Wen, X. Y., Jin, X. H., Liu, H., Lu, H. F., Liu, H. X., Zhou, J., Zeng, Y., Smith, P., Jackson, P. W., Gratzfeld, J., Sharrock, S., Xu, H. G., Zhang, Z. X., Guo, Q. F., Sun, W. B., Ma, J. S., Hu, Y. H., Zhang, Q. M., Zhao, L. N. (2019): Progress of implementation on the Global Strategy for Plant Conservation in (2011-2020) China. - Biological Conservation 230: 169-178.

[35] Simpson, E. H. (1949): Measurement of biodiversity. - Nature 163: 688.

[36] Slade, A. J., Hutchings, M. J. (1987): The effects of nutrient availability on foraging in the clonal herb Glechoma hederacea. - Journal of Ecology 75: 95-112.

[37] Sun, J. Q., Chen, Q., Li, H. Y., Chang, Y. F., Gong, H. D., Song, L., Lu, H. Z. (2019): Progress on the clonality of epiphytic ferns. - Biodiversity Science 27(11): 1184-1195.

[38] Thomas, J. S., Stohlgren, S. K. (2013): Endangered Plants. - Encyclopedia of Biodiversity 2: 205-215.

[39] Wang, X. B., Yu, S. L., Chen, H. W. (2007): The Basic Characteristics and Prospect of Effective Management of Nanling Reserve, Guangdong Province. - Guangdong Forestry Science and Technology 2: 90-93.

[40] Wang, K. (2010): Chemical constituents of six plants, Brainea insignis and Hypericum lagarocladum. - Kunming Institute of Botany, Chinese Academy of Science. 
[41] Wang, F. G., Chen, Z. M., Chen, H. F., Xing, F. W., Dong, A. Q. (2013): Flora and Vegetation of Nanling National Nature Reserve. - Huazhong University of Science and Technology, Wuhan.

[42] Wang, J. J., Zhang, M. R., Yi, L. T., Zhang, R. M., He, Y. H. (2021): Effects of light and nitrogen on clonal reproduction characteristics and biomass allocation of Dicranopteris dichotoma. - Journal of Zhejiang A\&F University 38(01): 74-83.

[43] Wu, Z. Y., Sun, H., Zhou, Z. K., Li, D. S., Peng, H. (2010): Floristics of Seed Plants from China. - Science press, Beijing.

[44] Zang, D. K. (1998): A preliminary study on the ferns flora in China. - Acta Botanica Boreali-Occidentalia Sinica 03: 148-154.

[45] Zhang, J. L. (2010): Calculation of biodiversity index by R software. - Available at http://blog.scoencenet.cn/blog-255662-310032.html (accessed: Juiy 2020).

[46] Zhang, J. (2018): Effects of various canopy densities on the understory vegetation development and decomposition of Pinus massoniana foliar litter in the Pinus massoniana plantations. - Sichuan Agricultural University, Sichuan.

[47] Zhang, L. M., Lu, H. Z., Alpert, P., Song, L., Liu, W. Y., Yu, F. H. (2019): Higher benefits of clonal integration in rhizome-derived than in frond-derived ramets of the tropical fern Bolbitis heteroclite. - Flora 257: 151415.

[48] Zhao, H. R., Yang, Y. L. (1985): New Taxa and New Combinations of Indocalamus from China. - Multiple Stars Across the H-R Diagram, pp. 232.

[49] Zhou, H. (2011): A study on the characters based on leaf index of robinla pseudoacacia. Northwest Agricultural and Forest University, Chongqing.

[50] Zhou, N., Li, L. Q., Wang, Y. D. (2015): The rise and fall evolution of family Pteridaceae. - Big Nature 4: 48.

[51] Zhou, J. T. (2019): Plant diversity and community characteristics of Yellow and Tianmu mountains in East China. - Zhejiang University, Zhejiang.

\section{APPENDIX}

Table A1. Overview of the sample plots of Dipteris chinensis at the Nanling National Nature Reserve, southern China

\begin{tabular}{c|c|c|c|c|c|c}
\hline Site & Latitude \& longitude & Elevation(m) & Slope $\left(^{\circ}\right)$ & Aspect & $\begin{array}{c}\text { Soil } \\
\text { thickness(m) }\end{array}$ & $\begin{array}{c}\text { Depth of the } \\
\text { bedrock (m) }\end{array}$ \\
\hline Down slope & $24^{\circ} 44^{\prime} 23^{\prime \prime} \mathrm{N}, 112^{\circ} 53^{\prime} 34^{\prime \prime} \mathrm{E}$ & 889 & 15 & Northeast & $>0.5$ & $>5.0$ \\
Middle slope & $24^{\circ} 44^{\prime} 25^{\prime \prime} \mathrm{N}, 112^{\circ} 53^{\prime} 36^{\prime \prime} \mathrm{E}$ & 863 & 20 & Northeast & $>0.5$ & $>5.0$ \\
Upslope & $24^{\circ} 44^{\prime} 45^{\prime \prime} \mathrm{N}, 112^{\circ} 54^{\prime} 40^{\prime \prime} \mathrm{E}$ & 823 & 30 & Northeast & $>0.5$ & $>5.0$ \\
\hline
\end{tabular}

